\title{
DOES CAFFEINE INTAKE INFLUENCE MENTAL HEALTH OF MEDICAL STUDENTS?
}

\author{
Zaleha Md Isa ${ }^{*}$, Afraah Amani Anuar², Amirul Danial Azmi², Sanjeevaraj Tamil Selvan², Noor Shafiqah \\ Hisham ${ }^{2}$ and Yong Zi Qing ${ }^{2}$
}

\author{
${ }^{1}$ Department of Community Health, Faculty of Medicine, Universiti Kebangsaan Malaysia Medical Centre, 56000 Kuala \\ Lumpur, Malaysia. \\ ${ }^{2}$ Faculty of Medicine, Universiti Kebangsaan Malaysia Medical Centre, 56000 Kuala Lumpur, Malaysia.
}

*Corresponding author: Zaleha Md Isa

Email: zms@ppukm.ukm.edu.my

\begin{abstract}
Caffeine (1,3,7-trimethylxanthine) consumption among students is known to increase alertness and energy, as well as to alleviate stress. There has been an increase of caffeine consumption amongst young adults. Currently, there are no studies regarding caffeine consumption and its influence on mental health among Malaysians. We aimed to determine the relationship of caffeine consumption with depression, anxiety and stress among medical students. A cross sectional study was conducted among medical students in the Faculty of Medicine, Universiti Kebangsaan Malaysia. Data were collected via an online survey using two questionnaires, namely the semi-quantitative Food Frequency Questionnaires on Caffeine Intake and Depression, Anxiety and Stress Scale (DASS-21). A total of 262 medical students completed the survey. The prevalence of depression, anxiety and stress was $9.2 \%, 16.8 \%$ and $1.1 \%$, respectively. Majority of students (98.5\%) consumed caffeine from coffee, tea, soft drinks, energy drinks and chocolate drinks/food. The median daily caffeine consumption among consumers was $67.98\left(25^{\text {th }}, 75^{\text {th }}\right.$ percentile: $\left.24.83,139.71\right) \mathrm{mg} /$ day. There was a significant association between race and anxiety $(p=0.038)$ in which the Malay students had the highest prevalence $(21.1 \%)$, followed by Indian (16.1\%), other races (15.4\%) and Chinese students (3.8\%). Caffeine consumption did not influence mental health of medical students in this study. Anxiety is the most prominent mental health problem among them. We recommend a programme tailored to medical students in recognising symptoms of mental health problems so that early intervention can be carried out.
\end{abstract}

Keywords: Caffeine, 1,3,7-trimethylxanthine, mental health, medical students

\section{INTRODUCTION}

Caffeine (1, 3, 7-trimethylxanthine), a central nervous system (CNS) stimulant of the methylxanthine class and a natural alkaloid, is the most widely consumed psychoactive substance around the world. The most popular caffeinecontaining beverage is coffee, which contains more caffeine than most other beverages, and is consumed more widely and frequently. The major source of caffeine consumption are beverages like tea, carbonated soft drinks and energy drinks, while chocolate and other cocoa-containing foods contribute fewer amounts of caffeine to the diet. Caffeine is a psychoactive drug that, according to research, can cause or enhance anxiety and other stress-related signs and symptoms in several ways. It is classified as a nootropic as well because it sensitizes neurons and provides mental stimulation. Caffeine's main mechanism concerns antagonizing adenosine receptors. Adenosine causes sedation and relaxation when it acts upon its receptors, located in the brain while caffeine prevents this action and causes alertness and wakefulness. Medical students are known to lead a stressful life that requires an extended period of wakefulness and a high level of concentration to cope with their academic workload. Therefore, medical students are one of the most susceptible and more prone to consume caffeine than others among college students ${ }^{1}$.

According to the Malaysian Ministry of Health statistics, there was an increase in mental health problems among Malaysian students from one in ten in the year 2011 to one in five in the year $2016^{2}$. There are a number of local studies that look at mental health problems amongst Malaysian undergraduates. A study done in Malaysia showed that the prevalence of psychological stress among medical students was high while psychological stress was also significantly associated with depression ${ }^{3}$. Anxiety is another one of the most common psychiatric problems faced by medical students. One study shows that the global prevalence rate of anxiety among medical students was $33.8 \%$ and it is most prevalent among medical students from the Middle East and $\mathrm{Asia}^{4}$. Based on a study among Malaysian undergraduates, it was found that the prevalence rate of perceived stress was at $37.7 \%$. In the study, it was also found that perceived stress among first year and female students were higher than others ${ }^{5}$. A study in 
Kelantan, Malaysia found that the prevalence of depression among medical students was $22.0 \%{ }^{6}$.

There are a number of known factors that contribute to the rise in mental health problems especially amongst undergraduates. The main contributors for mental health problems are academic pressure, financial burden, increased accessibility of higher education, increased femaleto-male ratio, increased use of technology and dramatic change in lifestyle of students ${ }^{7}$. A study in Kota Bharu, Kelantan found that there was a high prevalence of stress among secondary school students, the major stressors were related to academic and contributing factors of stress were related to school training, students and parents ${ }^{8}$.

The increasingly worrying number of medical students affected by mental health problems is a call for concern. Therefore, there is a need to look into all possible factors that may play a role in worsening this issue. Thus, this study aims to evaluate the relationship of caffeine intake with depression, anxiety, and stress among medical students in Universiti Kebangsaan Malaysia.

\section{METHODS}

This is a cross-sectional study conducted among medical students in the Faculty of Medicine, Universiti Kebangsaan Malaysia. The sampling unit is individual medical student who was above the age of 18 at the time of the study. Those who were clinically diagnosed with a psychiatric disorder such as major depressive disorder, panic disorder, generalised anxiety disorder and/or bipolar disorder were excluded from this study. Data were collected by convenience sampling method via an online survey. Questionnaires comprising of sociodemographic information, Food Frequency Questionnaires (FFQ), Depression, Anxiety and Stress Scale (DASS 21) were distributed to all medical students from year 1 until year 5 .

The sample size was calculated to be 256 students within a population of 1000 medical students. The confidence interval was $95 \%$ with a $4.5 \%$ margin of error. Consent was obtained from the respondents before starting the survey. A total of 262 medical students had completed the survey. A pilot study was conducted before-hand to identify the caffeinated food and drinks regularly consumed by the medical students. The pilot study was done among 30 medical students who were not involved in the main study and their 24-hour dietary intake was recorded for 3 days ( 2 working days and 1 weekend day). A set of FFQs was constructed based on the findings from the 24-hour dietary intake. Subsequently, the respondents were required to answer the newly developed FFQs and the results were correlated with the 24-hour dietary intake. Foods that were not commonly taken by the respondents were taken out from the FFQs. The edited version of the FFQs was then distributed to the respondents for the main study. The total amount of caffeine intake per day for different beverages and food were calculated based on the Malaysian Food Composition Database (MyFCD), followed by multiplication with the intake frequency. Thus, an average of caffeine intake per day for each respondent was obtained.

The population of medical students were also given a Depression-Anxiety-Stress Scale (DASS 21) questionnaire. DASS 21 questionnaire was used to screen for the presence of depression, anxiety and/or stress symptoms. Data were collected for all three parts of the questionnaire. For anxiety, any value above 7 was grouped as "Having anxiety symptoms" and values less than or equal to 7 were grouped as "Not having anxiety symptoms". For stress, any value above 14 was grouped as "Having stress" whereas values less than or equal to 14 were grouped as "Not having stress". For depression, any value above 9 was grouped as "Having depression" while values less than or equal to 9 were grouped as "Not having depression". Age, gender, race, previous high school status and year of study were also collected as descriptive data for this study. Data were analysed using SPSS software (Statistical Package for Service Solutions version 22.0). Categorical variables were presented in frequencies and percentages. Continuous variables were presented as mean and standard deviation or median and interquartile range according to normality of distribution. Mean differences between two exposure groups were analysed using independent $\mathrm{t}$-test or Mann-Whitney $\mathrm{U}$ test. Differences in proportions between two exposure groups were analysed using chi-squared test or chisquared test with continuity correction. A $p$ value less than 0.05 was considered statistically significant.

\section{RESULTS}

The total number of respondents who completed the study was 262 medical students with $63.4 \%$ Malay, $19.8 \%$ Chinese, $11.8 \%$ Indian and $5.0 \%$ Others. Table 1 shows the distribution of the respondents based on their race, gender, year of study (preclinical or clinical) and previous high school status (non-boarding or boarding school). Our respondents were predominantly female students at $73.3 \%$ of the total respondents. Clinical students made up $60.7 \%$ of the respondents and $62.6 \%$ were not from boarding schools previously. 
Table 1: Sociodemographic characteristics of the respondents $(N=262)$

\begin{tabular}{llll}
\hline Sociodemographic variable & & Frequency (f) & Percentage (\%) \\
\hline Gender & Male & 70 & 26.7 \\
& Female & 192 & 73.3 \\
\hline Race & Malay & 166 & 63.4 \\
& Chinese & 52 & 19.8 \\
& Indian & 31 & 11.8 \\
& Others & 13 & 5.0 \\
\hline Year of study & Pre-clinical & 103 & 39.3 \\
& Clinical & 159 & 60.7 \\
\hline Previous high school & Non-boarding school & 164 & 62.6 \\
& Boarding school & 98 & 37.4 \\
\hline
\end{tabular}

The prevalence of depression among medical students was $9.2 \%$ (24 out of 262) (Table 2). The results trend shows that the Malay respondents had a higher prevalence of depression $(10.8 \%)$ as compared to the non-Malay respondents $(6.2 \%)$. Female respondents had a higher prevalence of depression $(9.9 \%)$ than male respondents $(7.1 \%)$, while medical students in clinical years had a higher prevalence of having depression (11.3\%) compared to preclinical year students (5.8\%). Medical students who attended non-boarding school previously were at a higher prevalence of having depression $(11.0 \%)$ as compared to students who attended boarding school (6.1\%). However, all the associations were not significant in this study.

Table 2: Prevalence of depression and its associated factors $(\mathrm{N}=262)$

\begin{tabular}{|c|c|c|c|}
\hline Characteristics & $\begin{array}{l}\text { Depressed } \\
(n=24) \\
f(\%)\end{array}$ & $\begin{array}{l}\text { Not depressed } \\
(n=238) \\
f(\%)\end{array}$ & p-value \\
\hline \multicolumn{3}{|l|}{ Race } & \multirow[t]{3}{*}{0.222} \\
\hline Malay & $18(10.8)$ & $148(89.2)$ & \\
\hline Non-Malay & $6(6.2)$ & $90(93.8)$ & \\
\hline \multicolumn{3}{|l|}{ Gender } & \multirow[t]{3}{*}{0.494} \\
\hline Male & $5(7.1)$ & 65 (92.9) & \\
\hline Female & $19(9.9)$ & $173(90.1)$ & \\
\hline \multicolumn{3}{|l|}{ Year of study } & \multirow[t]{3}{*}{0.132} \\
\hline Clinical & $18(11.3)$ & $141(88.7)$ & \\
\hline Pre-clinical & $6(5.8)$ & $97(94.2)$ & \\
\hline \multicolumn{3}{|l|}{ Previous high school } & \multirow[t]{3}{*}{0.188} \\
\hline Boarding school & $6(6.1)$ & $92(93.9)$ & \\
\hline Non-boarding school & $18(11.0)$ & $146(89.0)$ & \\
\hline
\end{tabular}

Table 3 shows that the prevalence of anxiety among medical students was $16.8 \%$ (44 out of 262). Malay respondents had a significantly higher prevalence of anxiety which was $21.1 \%$ as compared to the nonMalays $(9.4 \%)(p=0.039)$. The trend shows that the female respondents had a higher prevalence of anxiety $(18.8 \%)$ than the male respondents $(11.4 \%)$. Medical students in pre-clinical years had a higher prevalence of anxiety $(17.5 \%)$ as compared to clinical year students (16.4\%), while medical students who attended boarding school previously were at a higher prevalence of anxiety $(20.4 \%)$ as compared to students who attended non-boarding school (14.6\%). However, these associations were not significant.
The prevalence of stress among medical students was $1.1 \%$ ( 3 out of 262) (Table 4 ). The trend shows that the Malay respondents had a higher prevalence of stress $(1.2 \%)$ compared to the non-Malays $(1.0 \%)$. The male respondents had a higher prevalence of stress $(1.4 \%)$ than the female respondents $(1.0 \%)$. Medical students in clinical years had a higher prevalence of stress $(1.3 \%)$ as compared to preclinical year students (1.0\%). Medical students who attended non-boarding school previously were at a higher prevalence of stress $(1.8 \%)$ as compared to students who attended boarding school (0\%). However, there was no significant relationship between all sociodemographic variables and stress. 
Table 3: Prevalence of anxiety and its associated factors $(\mathrm{N}=262)$

\begin{tabular}{|c|c|c|c|}
\hline Characteristics & $\begin{array}{l}\text { Anxiety } \\
(n=44) \\
f(\%)\end{array}$ & $\begin{array}{l}\text { Non-anxiety } \\
(\mathrm{n}=218) \\
\mathrm{f}(\%)\end{array}$ & p-value \\
\hline $\begin{array}{ll}\text { Race } & \\
& \text { Malay } \\
& \text { Non-Malay }\end{array}$ & $\begin{array}{l}35(21.1) \\
9(9.4)\end{array}$ & $\begin{array}{l}131(78.9) \\
87(90.6)\end{array}$ & $0.039^{*}$ \\
\hline $\begin{array}{l}\text { Gender } \\
\text { Male } \\
\text { Female }\end{array}$ & $\begin{array}{l}8(11.4) \\
36(18.8)\end{array}$ & $\begin{array}{l}62(88.6) \\
156(81.2)\end{array}$ & 0.161 \\
\hline $\begin{array}{l}\text { Year of study } \\
\text { Clinical } \\
\text { Pre-clinical }\end{array}$ & $\begin{array}{l}26(16.4) \\
18(17.5)\end{array}$ & $\begin{array}{l}133(83.6) \\
85(82.5)\end{array}$ & 0.812 \\
\hline $\begin{array}{l}\text { Previous high school } \\
\text { Boarding school } \\
\text { Non-boarding school }\end{array}$ & $\begin{array}{l}20(20.4) \\
24(14.6)\end{array}$ & $\begin{array}{l}78(79.6) \\
140(85.4)\end{array}$ & 0.226 \\
\hline
\end{tabular}

*Significant value at $p<0.05$.

Table 4: Prevalence of stress and its associated factors $(\mathrm{N}=262)$

\begin{tabular}{|c|c|c|c|}
\hline Characteristics & $\begin{array}{l}\text { Stressed } \\
(n=3) \\
f(\%)\end{array}$ & $\begin{array}{l}\text { Not stressed } \\
(n=259) \\
f(\%)\end{array}$ & $\mathrm{p}$-value ${ }^{\mathrm{a}}$ \\
\hline $\begin{array}{ll}\text { Race } & \\
& \text { Malay } \\
& \text { Non-Malay }\end{array}$ & $\begin{array}{l}2(1.2) \\
1(1.0)\end{array}$ & $\begin{array}{l}164(98.8) \\
95(99.0)\end{array}$ & 1.000 \\
\hline $\begin{array}{l}\text { Gender } \\
\text { Male } \\
\text { Female }\end{array}$ & $\begin{array}{l}1(1.4) \\
2(1.0)\end{array}$ & $\begin{array}{l}69(98.6) \\
190(99.0)\end{array}$ & 0.795 \\
\hline $\begin{array}{l}\text { Year of study } \\
\text { Clinical } \\
\text { Pre-clinical }\end{array}$ & $\begin{array}{l}2(1.3) \\
1(1.0)\end{array}$ & $\begin{array}{l}157(98.7) \\
102(99.0)\end{array}$ & 0.831 \\
\hline $\begin{array}{l}\text { Previous high school } \\
\text { Boarding school } \\
\text { Non-boarding school }\end{array}$ & $\begin{array}{l}0(0) \\
3(1.8)\end{array}$ & $\begin{array}{l}98(100.0) \\
161(98.2)\end{array}$ & 0.178 \\
\hline
\end{tabular}

a Chi-square with continuity correction

The prevalence of caffeine intake among the medical students was $98.5 \%$ ( 258 out of 262 ) and the median concentration of caffeine intake among the consumers was 67.98 (25th,75th percentile: 24.83 , 139.71) $\mathrm{mg} /$ day. Table 5 shows that male respondents consumed more caffeine per day, 90.00 $\mathrm{mg} /$ day, as compared to female respondents, 65.82 $\mathrm{mg} /$ day. However, there was no significant difference between the two genders $(p=0.126)$. Respondents who were depressed based on the DASS-21 score consumed more caffeine per day at a median of $87.66 \mathrm{mg} /$ day as compared to those who were not depressed at $66.07 \mathrm{mg} /$ day. However, the difference of caffeine consumption between those who were depressed and not depressed was not significant $(p=0.150)$. The respondents who were having anxiety consumed slightly more at 70.02 $\mathrm{mg} /$ day than those who did not have anxiety who consumed $67.42 \mathrm{mg} /$ day. However, the difference was not significant $(p=0.972)$. Respondents who were not stressed based on the DASS-21 score consumed caffeine per day at $68.19 \mathrm{mg} /$ day than those who were stressed $(11.13 \mathrm{mg} /$ day $)$. However, the difference was not significant $(p=0.146)$. 
Table 5: Depression, anxiety, stress and their association with caffeine intake $(\mathrm{N}=262)$

\begin{tabular}{|c|c|c|}
\hline Variables & $\begin{array}{l}\text { Caffeine intake }(\mathrm{mg} / \text { day }) \\
\text { Median }\left(25^{\text {th }} \text { percentile, } 75^{\text {th }} \text { percentile }\right)\end{array}$ & $\mathrm{p}$-value ${ }^{\mathrm{b}}$ \\
\hline $\begin{array}{l}\text { Gender } \\
\text { Male }(n=69) \\
\text { Female }(n=189)\end{array}$ & $\begin{array}{l}90.00(34.62,146.21) \\
65.82(19.30,137.39)\end{array}$ & 0.126 \\
\hline $\begin{array}{l}\text { Depression status } \\
\text { Depressed }(n=24) \\
\text { Not depressed }(n=234)\end{array}$ & $\begin{array}{l}87.66(36.75,227.38) \\
66.07(21.56,137.08)\end{array}$ & 0.150 \\
\hline $\begin{array}{l}\text { Anxiety status } \\
\text { Anxiety }(n=44) \\
\text { Non-anxiety }(n=218)\end{array}$ & $\begin{array}{l}70.02(26.96,124.67) \\
67.42(22.36,143.51)\end{array}$ & 0.972 \\
\hline $\begin{array}{l}\text { Stress status } \\
\text { Stressed }(n=3) \\
\text { Not stressed }(n=255)\end{array}$ & $\begin{array}{c}11.13\left(3.9,11.13^{c}\right) \\
68.19(25.70,143.24)\end{array}$ & 0.146 \\
\hline
\end{tabular}

\section{DISCUSSION}

The lack of literature on the association between caffeine and mental health issues was the main motivation behind this study. We quantified caffeine consumption by using a validated Food Frequency Questionnaires consisting of 18 different foods and beverages that contain caffeine. We then tried to correlate the total caffeine consumption per day to the prevalence of mental health issues which was screened using the DASS-21. Among the 262 medical students who responded, it was found that the prevalence of depression, anxiety and stress was at $9.2 \%, 16.8 \%$ and $1.1 \%$ respectively. We also found that most of the respondents, $98.5 \%$ specifically, consumed caffeine regularly.

The prevalence of mental health issues was significantly lower when compared to previous studies done in another public university in Malaysia ${ }^{9}$ and a private university in Malaysia ${ }^{10}$, both of which showed a high prevalence of depression, anxiety and stress. The study by Shamsuddin et al. ${ }^{9}$ showed a prevalence of depression, anxiety and stress at $37.3 \%, 63.0 \%$ and $23.7 \%$ respectively. The subsequent study by Fuad et al. ${ }^{10}$ observed a prevalence in depression, anxiety and stress at $60 \%$, $76 \%$ and $47 \%$ respectively. The results are tremendously different compared to the current study in our centre. However, even if the prevalence is significantly different, it is evident that there is a general trend among medical students to have higher prevalence of anxiety. We feel that though this shows the prevalence of mental health issues among medical students, it is still not very accurate as this is a cross sectional study, and the questionnaires were distributed during the examination week for the students. This could have had an impact on the prevalence of the individual mental health issues that we tested for. Meanwhile, although there was no significant association between depression and the students' demography, there is a trend showing that the Malay students, female, studied in clinical years, and from non-boarding school background had a higher prevalence of depression.

From this study, although the DASS questionnaire is not a diagnostic instrument, the prevalence of depression, anxiety and stress symptoms of moderate severity or above highlights the need for attention from health care professionals and the university administrative personnel. Early detection is consequential in reducing the possible morbidities from psychiatric disorders. Morbidities such as suicide, increased risk of substance abuse and increased risk of cardiovascular problems may prove to be fatal.

Majority of students $(98.5 \%)$ consumed caffeine from coffee, tea, soft drinks, energy drinks and chocolate drinks/food. The median daily caffeine consumption for consumers was $67.98 \mathrm{mg} /$ day. In another study done in a Malaysian private medical school, it was found that most $(43 \%)$ of the participants consumed less than $100 \mathrm{mg} /$ day of caffeine ${ }^{11}$. Both are lower than a different study that was done whereby the average caffeine consumption was at $306.98 \mathrm{mg} / \mathrm{day}^{12}$. This large difference may be attributed to the different 
questionnaires used to measure caffeine consumption.

Despite multiple literatures in the past that associate caffeine intake to the occurrences of mental health issues, this study had no significant association between caffeine and depression, anxiety and stress. A recent study done in a private tertiary centre in Malaysia found that consumers of caffeinated energy drinks are likely to get psychological distress ${ }^{13}$. However, a few other studies showed that caffeine consumption was significantly associated with decreased risk of depression ${ }^{14}$, and that caffeine consumption acts as an independent protective factor for depression ${ }^{15}$. The fact that our data had no statistical significance can be attributed to a lot of different factors, one of which is the major limitation of our study; the limited number of respondents.

A study reported that caffeine consumption was associated with increased anxiety symptoms in young adult males ${ }^{16}$. Another review reported there is a substantial literature documenting the anxiogenic effects of caffeine in both experimental and realistic situations ${ }^{17}$. The lack of correlation of this study with the findings from previous literature can be attributed to the vast coping mechanisms that the respondents have. The low incidence of depression, anxiety and stress may be due to the Personal and Professional Development (PPD) module that the medical students have been exposed as part of the curriculum. A local study carried out on the efficacy of such modules revealed that intervention programmes improved students' reflective skills which could consequently lead to better coping mechanisms to mental health issues among the students ${ }^{18}$.

\section{LIMITATION OF STUDY}

There are some limitations in this study. Firstly, we had difficulties in gathering information regarding caffeine concentration in food and beverages due to lack of relevant literature on the subject matter. We suggest referring the American Food and Drug Administration database and company information for caffeine concentration of common foods and drinks. It was also noted that in order for us to have established results, this study needs a larger sample size and a higher response rate among the respondents so that we can capture sufficient data required in this study. The findings of this study would be useful in recognising the effect of caffeine that can be seen among medical students in local universities. Local literature on the subject matter is not available specifically regarding the effect of caffeine on mental health among medical students. The data that was presented in this study can be used to make specific, targeted intervention on the students who are in need of it. It is also evident that more research has to be done locally on caffeine as we need data which can be correlated with our population.

\section{CONCLUSION}

There is no significant association between caffeine consumption and mental health in this study. Previous literature reported that caffeine plays a significant role in influencing mental health. Our study also brought into light the prevalence of mental health issues among medical students. Targeted intervention such as counselling, relevant psychotherapies and pharmacological treatment should be carried out to tackle these issues early on. More research has to be done locally on the effect of caffeine so that accurate recommendations on caffeine intake can be given to the local consumers.

\section{REFERENCES}

1. Yousif Al-turki, Basel A, Abdulrhman A, Mazi A, Abdulsalam A, Abdulrahman A, Abdulelah A, Mohammed A. Caffeine Habits among Medical Students in King Saud University. College of Medicine, King Saud University, Riyadh, Saudi Arabia. 2013.

2. Bernama. Mental health of Malaysian students cause of worry: Health Ministry. New Straits Times. Published. 2016 Accessed June 10, 2021. https: / /www.nst.com.my/news/2016/09 /172683/mentalhealthmalaysianstudents causeworryhealthministry.

3. Sherina MS, Rampal L, Kaneson N. Psychological Stress Among Undergraduate Medical Students. Med J Malaysia 2004 59(2): 207 - 211.

4. Quek TT, Tam WW, Tran BX, Zhang M, Zhang Z, Ho CS, Ho RC. The Global Prevalence of Anxiety Among Medical Students: A Meta-Analysis. International Journal of Environmental Research and Public Health 2019 16(15): 2735.

5. Jia YF, Loo YT. Prevalence and determinants of perceived stress among under-graduate students in a Malaysian university. Journal of Health and Translational Medicine 2018 21(1). https: / /jummec.um.edu.my/article/view /11016 
6. Yusoff MSB, Rahim AFA, Yaacob MJ. The prevalence of final year medical students with depressive symptoms and its contributing factors. International Medical Journal 2011 18(4): 305-309.

7. Alicia KF. A suffering generation: Six factors contributing to the mental health crisis in North American higher education. The College Quarterly, Seneca College of Applied Arts and Technology 2013 16(1).

8. Yusoff MSB, Hamid AHA, Rosli NR, Zakaria NA, Rameli NAC, Rahman NSA, Rahim AFA, Rahman AA. 2011. Prevalence of stress, stressors and coping strategies among secondary school students in Kota Bharu, Kelantan, Malaysia. Int J Stud Res 1(1): 23 - 28.

9. Shamsuddin K, Fadzil $F$, Ismail, WSW, Shah SA, Omar K, Muhammad NA, Jaffar A, Ismail A, Mahadevan R. Correlates of depression, anxiety and stress among Malaysian university students. Asian Journal of Psychiatry 2013 https://doi.org/10.1016/j.ajp.2013.01.0 14.

10. Fuad MD, Al-Zurfi BMN, Abdelqader MA, Abu Bakar MF, Elnajeh M, Abdullah MR. Prevalence and Risk Factors of Stress, Anxiety and Depression among Medical Students of a Private Medical University in Malaysia. Education in Medicine Journal 2015

https://doi.org/10.5959/eimj.v7i2.362

11. Ching CS, Ling TS. Caffeine Consumption and Knowledge among First Year Medical Students in a Malaysian Private Medical School. Asian J Med Heal Serv 2021 4(1):119-127.

12. Atikahramli NA, Sriperumbuduru VPK, Ghazi HF, Dalayi NJ. A study of caffeine consumption patterns and dependence among management and science university students. Indian J Forensic Med Toxicol 2019 13(1):101-105. doi:10.5958/0973-9130.2019.00021.5

13. Norshafarina SK, Ahmad Aisar AH, Neni WS. Association between the consumption of caffeinated energy drink, daytime sleepiness and psychological distress level among universities students in Shah Alam, Selangor. J Manag Sci 2018 16(2):39-45.
14. Wang L, Shen X, Wu Y, Zhang D. Coffee and caffeine consumption and depression: A meta-analysis of observational studies. Australian and New Zealand Journal of Psychiatry 2016 https://doi.org/10.1177/00048674156031 31

15. Grosso G, Micek A, Castellano S, Pajak A, Galvano F. Coffee, tea, caffeine and risk of depression: A systematic review and dose-response meta-analysis of observational studies. Molecular Nutrition and Food Research 2016 https: / / doi.org/10.1002/mnfr.201500620

16. Trapp GSA, Allen K, O'Sullivan TA, Robinson M, Jacoby $P$, Oddy WH. Energy drink consumption is associated with anxiety in australian young adult males. Depression and Anxiety 2014 https://doi.org/10.1002/da.22175

17. Winston AP, Hardwick E, Jaberi N. Neuropsychiatric effects of caffeine. Advances in Psychiatric Treatment 2005 https://doi.org/10.1192/apt.11.6.432

18. Siraj HH. Self-awareness and reflective skills in the promotion of personal and professional development of future medical professionals. Education in Medicine Journal 2013 https://doi.org/10.5959/eimj.v5i4.171. 